\title{
Family Education Optimization from the Perspective of Complex Discrete Computational Thinking
}

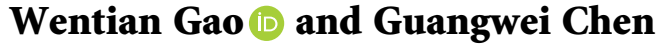 \\ School of Zhengzhou Railway Vocational \& Technical College, Zhengzhou, Henan 451460, China \\ Correspondence should be addressed to Wentian Gao; 10128@zzrvtc.edu.cn
}

Received 18 January 2022; Revised 9 February 2022; Accepted 11 February 2022; Published 2 March 2022

Academic Editor: Gengxin Sun

Copyright (c) 2022 Wentian Gao and Guangwei Chen. This is an open access article distributed under the Creative Commons Attribution License, which permits unrestricted use, distribution, and reproduction in any medium, provided the original work is properly cited.

\begin{abstract}
Family education relationship is a general term for all the relationships that occur around family education activities. The establishment of family education relationship plays an important role in the activity process and effect of family education and will have a profound impact on children's physical and mental development. The study of family education relationship is an important issue that cannot be ignored in the study of family education theory. In order to enhance the effectiveness of family education, it is an objective requirement of theory and practice to rationally analyze and optimize the contemporary family education relationship from the perspective of communication theory. The introduction of communication theory into the field of family education will help to change the actual situation of lack of communication and barrier in contemporary family education relationship and also provide a new idea and perspective for the research and solution of other related problems in family education. Starting from the research and discussion of the basic theory of the relationship between communication and family education, this paper analyzes the concept and characteristics of family education relationship in detail, analyzes and examines the family education relationship in history, and establishes a basic understanding of family education relationship. On the basis of the research of the relevant basic theories, the paper explores and analyzes the current situation and reasons of the lack of communication and the blocking of the contemporary family education relationship. From the perspective of communication, it investigates the contemporary family-educational relationship, clarifies that the basic structure of the family-educational relationship is the unity of the internal interpersonal organizational relationship structure, the psychological relationship structure, and the activity process structure, and examines the current situation of the basic structure one by one. This paper proposes that, with the development of the times and society, the contemporary family education relationship has a huge development compared with the historical family education relationship, reflecting the characteristics of the times such as democracy, but there is still a lack of communication and barriers. Then it analyzes the various concrete manifestations of the lack of communication and the blocking situation in the contemporary family education relationship and its adverse consequences to family education. This paper verifies the influence of computational thinking on the optimization mechanism of family education and demonstrates the feasibility and effectiveness of computational thinking in family education. This optimizes the family education mechanism from the perspective of computational thinking and provides a research case with reference value for follow-up research.
\end{abstract}

\section{Introduction}

With the booming development of information technology, humankind has long since entered the information age. Information technology has brought changes to our lives in every aspect, and at the same time, it has also brought new opportunities and challenges to education. How to make use of information technology to promote the development of education and provide a constant impetus for the reform of education has become a common concern of the global education community [1]. The concept of life refers to people's fundamental views and opinions on life issues, and it has positive significance for people to better understand life, practice life, and perfect life. Family is the place where everyone lives and grows up from birth, and family education plays a very important role in the development of 
personal character and the formation of life view. Computational thinking is an important topic of current academic interest [2]. Although there is no single definition, most researchers define "computational thinking" as a way of thinking about problem-solving, a thinking process that uses abstraction, generalization, decomposition, algorithmic thinking, and debugging (error detection and correction). As computational thinking and approaches continue to permeate the home, it is becoming an inevitable trend to incorporate computational thinking into home education. Computational thinking is also gradually being established as a fourth competency after reading, writing, and arithmetic, a way of thinking about the world and problem solving that can be learned and mastered by all people and is not limited to the computer professional field. This also shows that computational thinking, like reading, writing, and arithmetic in our daily lives, is an ability that everyone should have.

Throughout the thousands of years of our nation's history, excellent traditional culture has played a unique role, and family education has been considered one of the indispensable factors in the continuity and growth of our nation [3]. At the same time, our patriarchal ancestors have also accumulated countless praiseworthy good family traditions in the long history with their rich practices, adding a unique touch to the development and growth of the nation. Nowadays, although times have changed and society has changed, the family is the cell of society, and the family is the foundation of the country. Computational thinking is an important topic of current academic interest. Although there is no single definition, most researchers define "computational thinking" as a way of thinking about problem-solving, a thinking process that uses elements of abstraction, generalization, decomposition, algorithmic thinking, and debugging (error detection and correction). The disintegration of the patriarchal society, the change of family concept, the prevalence of family individualism, and the intergenerational tilt of family focus have made family education face a series of crises in the inheritance and innovation of family ethics: neglect of kinship, lack of filial respect for parents and elders, lack of family honor; parents' lack of education for their children's growth, one-sided indulgence, emphasis on intelligence over morality; children's poor self-care ability, selfishness, no ideal goals in life, lack of self; the children having poor self-care ability, selfishness, no ideal goal in life, lack of self-restraint, etc. In such a realistic situation, it is obvious that it is necessary and urgent to focus on family, family education, and family style [4]. Because family style and family education have a mutually reinforcing relationship, the family style has an irreplaceable role in family education; therefore, in the new era, how to achieve the inheritance and innovation of good family style in family education is undoubtedly an important topic with both theoretical significance and contemporary value.

The new era has promoted a new change in home education from imparting knowledge to inspiring thinking. The requirement of education in thinking education is to develop the information processing function of the human brain and to put the innovative capabilities of home education at the core [5]. It is pointed out that the four aspects of computational thinking, information awareness, information society responsibility, digital learning, and innovation are the subject core literacy of the IT curriculum, requiring families to be able to master the basic knowledge and skills of information technology, enhance information awareness, develop computational thinking, improve digital learning and innovation, and establish a correct sense of information society values and responsibilities through the learning of the IT curriculum [6]. Academic research on traditional family education has been limited to not only defining its connotation and identifying its functions, but also further analyzing the modern transmission of traditional family traditions, but little research has been done on how to realize the transmission and innovation of family traditions in the field of family education. Computational thinking is a kind of thinking ability that innovative talents must have [7]. Compared with the traditional teaching model, the education mode that families adopt the computational thinking method to cultivate children's computational thinking ability in family education is more efficient, and children can not only master the knowledge, but also learn to apply the computational thinking method to daily life implicitly, solve the relevant problems in life, and finally internalize this way of thinking.

\section{Related Works}

Traditional family education has demonstrated its power and value in the current social context. The excellent ideological resources embedded in traditional family education are the concrete embodiment of traditional virtues in the family and have important guiding significance for solving the problems and dilemmas of family education in contemporary society [8]. However, the changes of the times and the development of society have made the inheritance of the excellent ideological resources embedded in traditional family culture face many difficulties in the present; therefore, it is especially urgent to analyze the reasons for the difficulties encountered in the inheritance of traditional family education in the present and to propose reasonable solutions. The development of computational thinking assessment has been guided by certain methods and a practical basis, but compared to the research on computational thinking theory and education, the home education component is still relatively weak, and there are still some shortcomings in the existing research to be improved. At present, academic research on traditional family education has not only been limited to the definition of its connotation and the identification of its functions, but also further analysis of the modern transmission of traditional family ethics, but there is little research on how to realize the transmission and innovation of family ethics in the field of family education [9]. Many experts have reached a consensus that a harmonious and loving family atmosphere is most conducive to the growth of children [10]. The experience of love during the growth of infants and children will have a great impact on their entire life. Because it determines 
how we grow and develop, it is also about how we relate to ourselves, to others, and even to society. The importance of family education, especially the education of children, especially the development of their language skills, is important at an early age, and it is also believed that parents cannot shirk their responsibility to educate their children even if they are not well educated, but can make up for it in other ways that are beneficial to their children's development [11]. The "utopian" public education of children and the establishment of a collective family system was widely practiced, with particular attention to the impact of early family education on young children. During the Renaissance, early family education was formally incorporated into the framework of the educational system, and the study of early childhood family pedagogy was officially launched through a profound discussion of early childhood family education. It was fruitful in family education, advocating that parents should educate their children according to their abilities, emphasizing that education should be carried out in the context of socialism and productive labor, and exploring and studying the problems of family education under socialist conditions.

Computational thinking is an important skill that guides individuals in the twenty-first century in solving problems in everyday life, and it is crucial to develop computational thinking from the early school years [12]. Throughout the presentation, the development of computational thinking assessment is mainly reflected in three aspects: the definition of the level of developmental criteria, the proposal, and the practical application of assessment instruments. The reality of our education, however, is that it is mainly aimed at the homeschooling community, so that other standards are still needed to guide the assessment of computational thinking for the whole. Overall, these criteria inspire us to work in dimensions, stages, and levels when it comes to computational thinking in home education; the existence of the criteria can help us to effectively grasp the requirements for home education and set the tone for the development of home education [13]. However, to measure the performance of learners in practice, it is necessary to combine assessment methods to translate these criteria into fine-grained quantitative indicators. However, at this stage of the development of computational thinking assessment, there is already a certain amount of methodological guidance and practical basis, but compared to the theoretical and educational research on computational thinking, the home education component is still relatively weak, and there are still some shortcomings in the existing research that need to be improved. Considering the limited cognitive level of students in the lower grades of learning, the learning operation sheets are also designed to be presented with simple text and easyto-understand graphic drawings, etc. For computational thinking to be carried out successfully and for the promotion of computational thinking family education to be strengthened, the current problems need to be solved on time.

In terms of conceptual understanding, computational thinking is still a complex concept with multiple definitions, and the lack of a comprehensive and deep understanding of computational thinking often leads to a one-sided approach to the development of existing family education, with less attention paid to the noncognitive conceptual aspects of computing. In terms of the actual state of home education, the complex content structure of computational thinking shows that educational computational thinking cannot be measured in a single way alone. Therefore, in practice, more and deeper information about the development of home education can only be obtained through a combination of multiple approaches. The role of the tutor throughout the collaborative learning process is that of a facilitator of student learning and a leader of the teaching process, with the teacher assigning learning tasks and controlling the teaching process. In addition, with the core connotation of computational thinking, the emphasis on the process of problem-solving more than the outcome of problem-solving inspires us that homeschooling should be integrated throughout all aspects of problem-solving and focus on a combination of formative and summative assessment [14]. Yet most of the current research continues to adopt a single educational approach, focusing on summative education to reflect the development of homeschool thinking. Most of the practice studies related to computational thinking education that have been conducted focus on the role of evaluation on revealing the developmental patterns of the whole group. Current homeschooling is diverse, and homeschooling, including computational thinking, continues to evolve in a pluralistic education, so evaluating children's computational thinking solely based on behavioral performance observed or evidence collected by home parents is not comprehensive, but should integrate children's behavior in different contexts. To achieve this goal, it is not enough to rely on parents alone; children also need to be involved in the process, and this requires certain ways of guiding children to consciously collect and preserve evidence that demonstrates their competence.

\section{Design and Construction of an Optimization Model for Family Education from a Computational Thinking Perspective}

3.1. Computational Thinking Model Construction. If computational thinking is measured as a whole, it will not only affect the feasibility of the practical operation, but also reduce the validity of the assessment results, so it is necessary to decompose computational thinking before the assessment [15]. The core components of computational thinking can be decomposed to clarify the specific content of the computational thinking assessment. In addition, detailed descriptions of these elements, such as conceptual descriptions and definitions of developmental criteria levels, are needed to enrich the conceptualization of the components of computational thinking and facilitate the smooth implementation of the assessment. Finally, the assessment cannot be conducted without methodological guidance. After decomposing computational thinking into several subcompetencies, it is necessary to match these competencies with appropriate assessment methods. Because 
computational thinking is a combination of multiple competencies, its complex content structure dictates that a single form cannot be used to assess all aspects of computational thinking. Therefore, the first step in measuring computational thinking is to break it down into a set of welldefined and easily observed and measured competencies, skills, or literacies (collectively referred to as competencies). Before decomposing computational thinking, it is necessary to describe the need and feasibility of decomposing computational thinking as a prerequisite for and value of the decomposition exercise.

Not only has the development of computational thinking received a great deal of attention worldwide, but how computational thinking is assessed is also of great interest to researchers. The main methods of assessing computational thinking can be broadly classified into four categories: scale assessment, work analysis assessment, interview-based assessment, and question test assessment. Some of the more widely used scales for assessing computational thinking include the Computational Thinking Framework, the Computational Thinking Scale (CTS), the Computational Thinking Tests (CT), and the International Computational Thinking Tests, etc. However, it is worth pointing out that existing computational thinking scales have been developed mainly for more mature groups, and there is a lack of computational thinking scales for primary school students. It has been pointed out that the early focus on computational thinking was mainly at the higher education level, and there is no widely accepted standard for how computational thinking can be assessed for implementation at the K-12 level. It is also important to note that the current phase of research on the assessment of computational thinking at the K-12 level has largely been conducted using a multidimensional, hierarchical setting.

$$
P_{i}=f(r+c t)
$$

The most influential of the computational thinking assessment scales is the 2012 Scratch-based computational thinking 3D framework: computational concepts, computational practices, and computational ideas. Among the many definitions, the framework is based on visual and process thinking, which is highly operational in educational practice, and the computational concepts and computational practices are well aligned with the three-dimensional goals of teaching and learning. The framework provides some support and practical guidance for much computational thinking teaching and learning development from three levels: conceptual content, practical operation, and conceptual extension. The design process of the computational thinking-based home education activities is shown in Figure 1.

Teaching objectives refer to the specific expected results to be achieved by teaching itself, which influences the selection and arrangement of teaching contents [16]. In a sense, instructional goals can fully reflect the good hopes and value pursuits of the curriculum developers for the educational society. In this study, the overall goal of the curriculum is to enable students to use their hands and brains by manipulating physical programming tools, and in the process to develop students' computational thinking such as algorithmic thinking, disassembling thinking, abstract thinking, pattern recognition, and debugging evaluation, so that students can have the confidence to face complex problems and improve their problem-solving ability. A more representative study on the classification of teaching objectives is the taxonomy of educational objectives. He classified the instructional objectives into three domains: cognitive, affective, and motor skills. In this study, the design of teaching objectives will refer to the CSTA Computer Science Education Standards (K-2) and ISTE International Society for Technology in Education standards, and each lesson will combine the five major competencies of computational thinking (abstract thinking ability, pattern recognition ability, disassembling thinking ability, algorithmic thinking ability, and debugging and evaluation ability) with the three areas of knowledge and skills, process, and methods, and affective attitudes and values, respectively. Also, the five practical methods of computational thinking (fiddling, creating, debugging, persevering, and cooperating) are used to design the corresponding teaching objectives.

Lesson action sheets are learning task sheets that family members reflect on paper before doing hands-on tasks, as shown in Figure 2. They are designed primarily based on the lesson content of the current lesson to help family members better reflect and master the core elements of computational thinking. The lesson action sheets are designed to be easy to understand and do not involve complex text to fully accompany the lesson plan. They are also designed to be relevant to the cognitive characteristics and preferences of the family members and are accompanied by pictures and talk boxes to "interact" with the students and arouse their interest. From the very beginning of learning computational concepts such as action and sequence to the later part of the semester when computational concepts such as data, conditions, and parallelism are involved, students' ideas about completing their work range from simple to complex, from not thinking enough to thinking more and more clearly.

In this study, the learning operations sheet can be understood as a scaffold to help students complete their learning tasks and it is also an important piece of evidence that we use to track student learning. In each session, students first think independently by completing the learning task sheets and then actually test the correctness of the procedures by doing the actual operations based on the ideas in the task sheets. Given the limited cognitive level of students in the lower levels of learning, the learning worksheets are also designed to be presented with simple text and easyto-understand graphic drawings, etc. In the process of completing the learning task sheets, students develop the ability to think independently and it also helps them to be able to have the thinking of analyzing and decomposing the problem first in the future problem-solving process, which is also part of the computational thinking development.

Existing research shows that students only have a comprehensive initial understanding of computational thinking concepts from grade 3 onwards and that the enhancement of some of the thinking skills involved in 

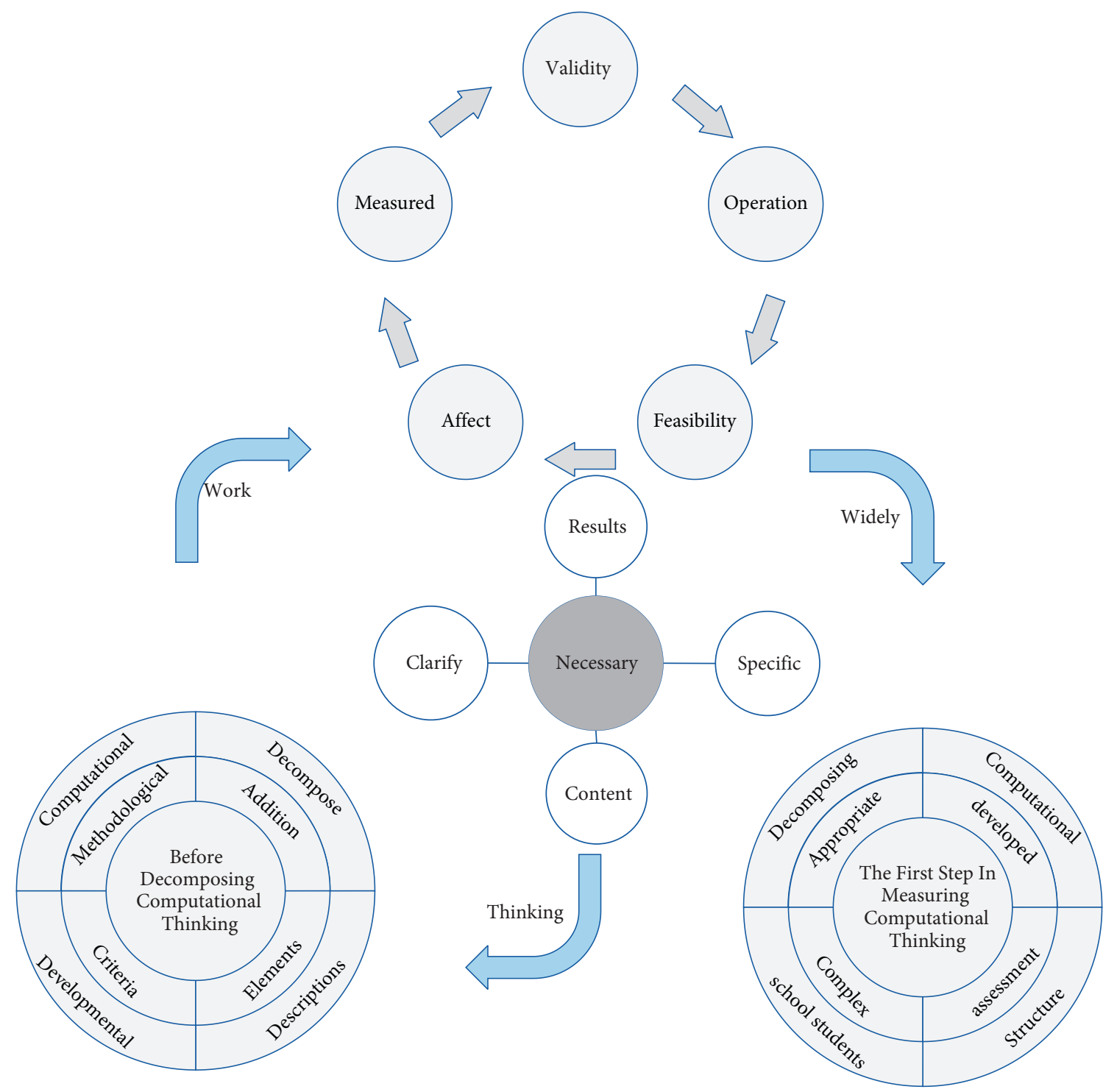

FIgURE 1: Flow of homeschooling activities for computational thinking.

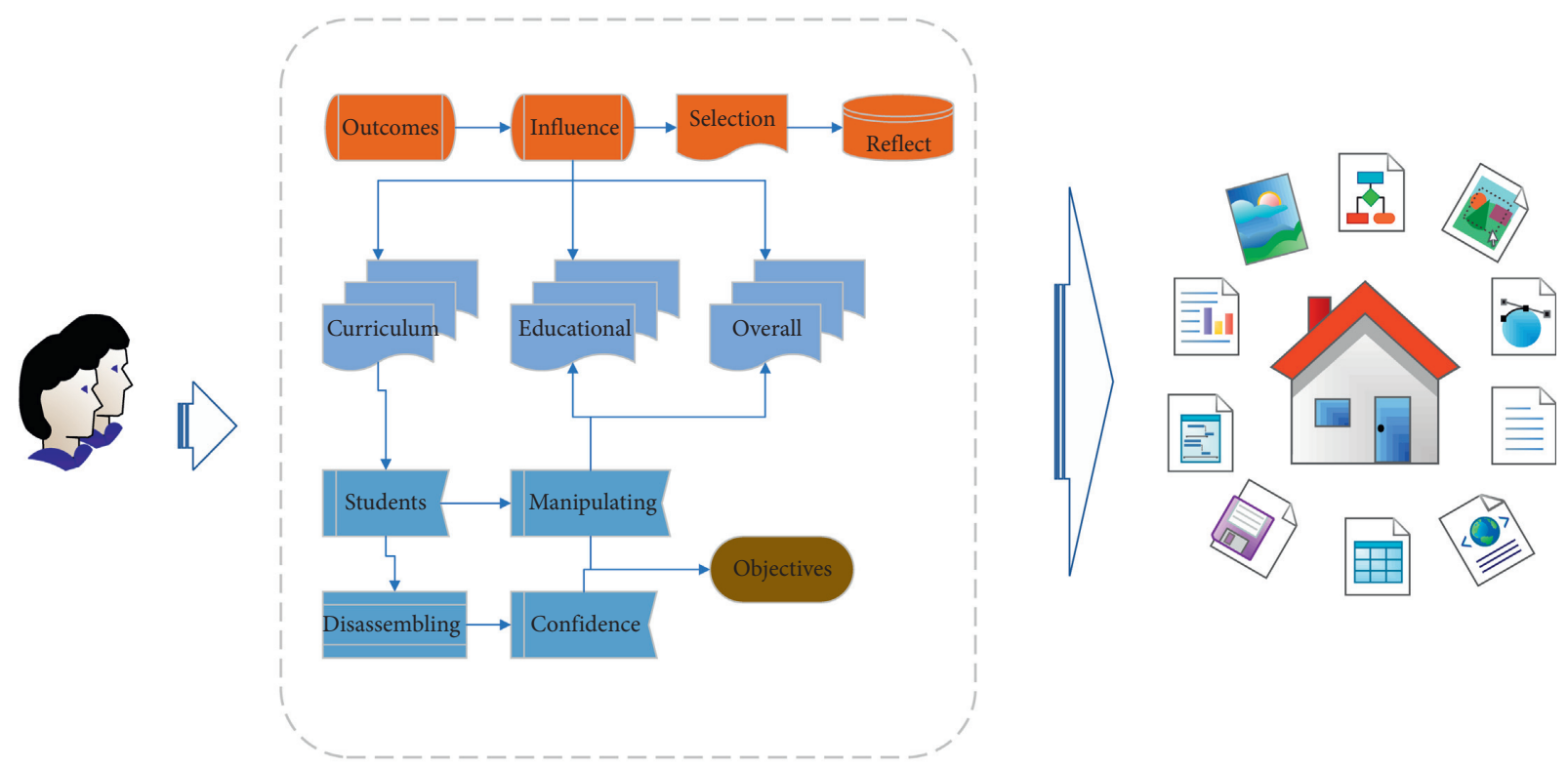

Figure 2: Example of a course operations sheet (task sheet). 
computational thinking is a relatively long and complex process that requires a great deal of further research and tracking in practice by subsequent scholars. Grade students' interest in simple programming, whether it enables students to have an awareness of computational thinking such as algorithmic thinking, disassembling thinking, abstract thinking, pattern recognition, and debugging evaluation, and gives students the confidence to face complex problems and improve their problem-solving skills [17]. A satisfaction survey at the end of the course was also necessary to gain insight into the effectiveness of the course, and after several surveys, the data were integrated to produce the satisfaction curve shown in Figure 3.

\subsection{Model Design of Family Education Optimization} Mechanism. The key to the effectiveness of family education guidance lies in whether the guidance personnel can grasp the laws of family education guidance and whether they are good at applying these laws to guide family education guidance. The understanding of the laws of family education guidance comes from the practice of family education guidance and the research on family education guidance. It should be noted that over the years there has been a tendency in the education sector to emphasize research on family education over research on family education guidance. In the research on family education guidance, the current situation, problems, causes, and countermeasures of family education guidance itself are more often studied from the perspective of parents receiving family education guidance, while very few studies on family education guidance are conducted directly from the perspective of family education guidance personnel. Likely, the results obtained from the different perspectives of guidance personnel and parents are different. To gain a more complete understanding of family education guidance, this study researches family education guidance through the leading party of family education guidance, i.e., guidance personnel, to understand the status of the family education guidance personnel team, the status of family education guidance personnel's family education guidance to parents, and the organization and management of guidance services at this stage, to provide a practical basis and target direction for the next step of professional family education guidance training [18].

Computational thinking is a representative method of scientific thinking, which contains all the characteristics of scientific thinking. The study and research of computational thinking, on the one hand, can facilitate the recognition of correlative factors between subjective representations of things and the analysis of cause-and-effect relationships between them; on the other hand, it helps us to analyze and explore the objective world. These two conditions need to be met to construct a collaborative thinking-based learning model. It is the need and call of the new curriculum reform to integrate the computational thinking approach into the current mature teaching and learning model to achieve the effect of improving the original teaching and learning model. For teachers, the competency profiles can help them design

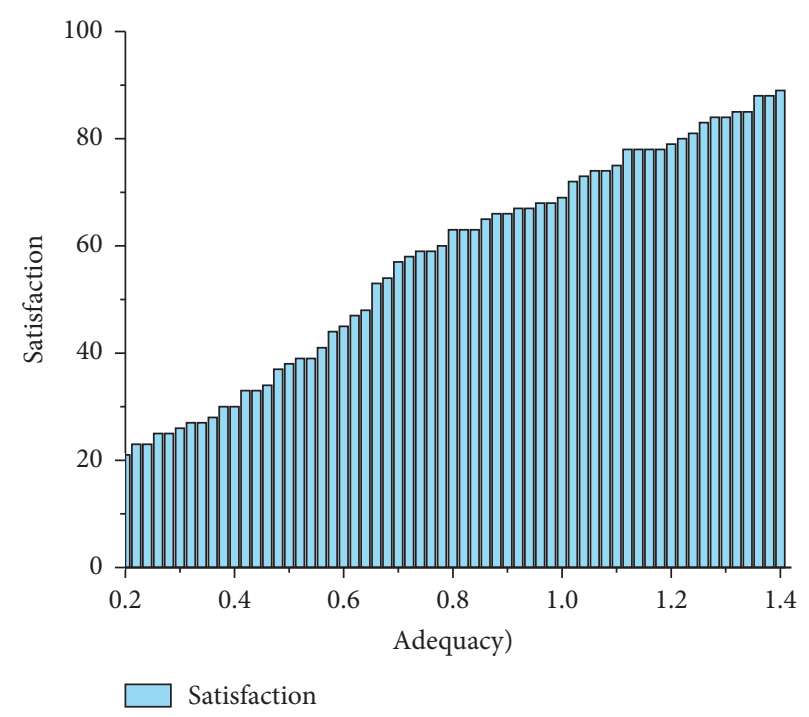

FIGURE 3: Satisfaction curve.

computational thinking assessment programs in a targeted manner; for learners, the competency profiles can help them establish an understanding of their competency development and planning, thus turning passive acceptance of assessment into active participation in assessment and increasing their motivation and initiative to participate in learning. The construction of a collaborative learning model based on computational thinking is a further study based on the theoretical foundation and practical operation of collaborative learning, exploring a collaborative learning model with thinking at its core, which is of great significance to the theory of collaborative learning and the development of computational thinking. The construction of a collaborative learning model based on computational thinking is based on four main aspects, as shown in Figure 4.

(1) Create and provide a good collaborative learning environment.

(2) Identify collaborative groups based on the content to ensure maximum inclusion of individual learners in the classroom.

(3) The collaborative family-based learning process includes the division of labor among group members by the group leader, the review of literature by each member, the analysis of learning, and the obtaining of solutions to problems group learning peers communicate with each other and sharing learning materials.

(4) In traditional collaborative learning, more attention is paid to the process of collaborative learning, and no special requirements are made for how to solve problems. In the collaborative learning model based on computational thinking, on the other hand, problem-solving with computational thinking methods is an extremely important link. To form a complete structural model, the other three links should also consider computational thinking 

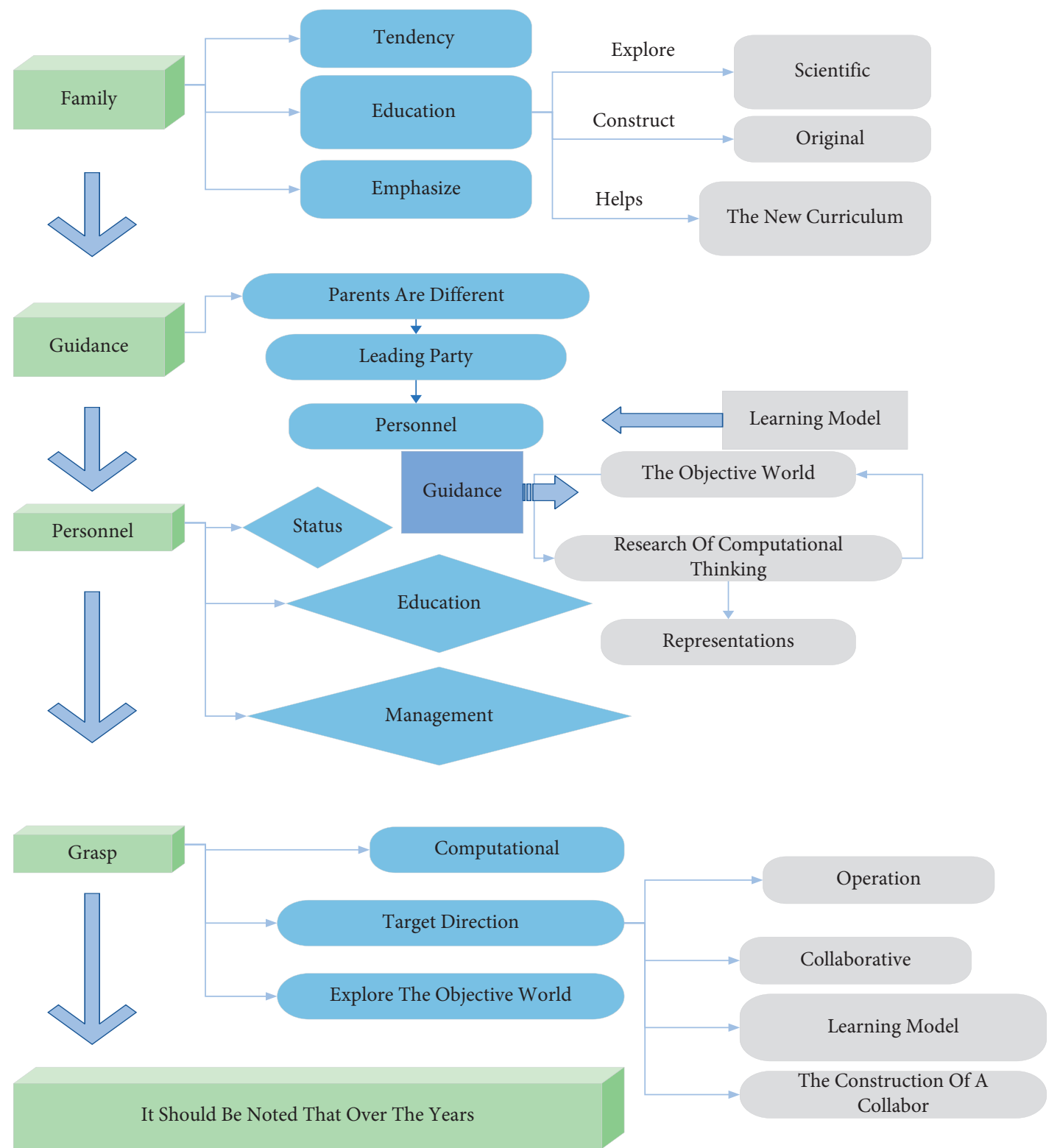

FIGURE 4: Rationale for the construction of a collaborative learning model based on computational thinking. Computational thinking-based web-based self-directed learning is based on the following aspects:

methods, and computational thinking should be integrated into the whole collaborative learning process.

Collaborative learning is learner-centered and emphasizes cooperative inquiry and resource sharing among individual learners. The role of the tutor in the whole collaborative learning process is that of a facilitator of student learning and a leader of the teaching process, who assigns learning tasks and controls the teaching process. The collaborative learning model usually contains four basic elements, which are the collaborative group, the members, the tutor, and the collaborative learning environment. To express the relationship between these four factors more visually, the authors use the following mathematical model to represent:

$$
C=F(A s, A t, A c)
$$

where $\mathrm{C}$ denotes the collaborative learning model, $\mathrm{F}$ () denotes a collaborative learning process function, $A s, A t$, and $A c c$ denote the action sets of learning members, tutors, and collaborative groups respectively, and $E$ denotes the collaborative learning environment. In the collaborative learning activity, the better and richer the content contained in $E$, the easier the learning and teaching process will be. As it can effectively achieve the learning goal under the tutor of $A t$, and the learning effect of the collaborative group can be effectively controlled and guaranteed. Typically, it has the following action sets and relationships:

$$
A_{G}=A_{i}(m+d+a+c+k)
$$


In a comprehensive comparison, the curriculum design among the three is organized by the organizers, and there is a certain arbitrariness in the curriculum design without a corresponding theoretical system and setting logic, while the learning effect of the learners is also uneven, which also affects the ability of family education instructors. Because it is shown in the above survey, the main sources of learning for family education instructors are the accumulation of experience and self-learning in the first two places and learning from professional institutions in the third place, but the overall learning effect is questionable because of the lack of scientific guidance and the difference in learners' ability to learn on their own. From the perspective of experts in training, the fact that different training units invite different experts and experts to teach in different fields leads to a large variation in training content. This is also a realistic manifestation of the lack of family education guidance theory. The activities of family education connote the task of transferring knowledge and skills, and a standardized curriculum is an important guarantee for transferring knowledge to most parents. From the arrangement of curriculum content, we can find that the current curriculum around the world has a strong arbitrary nature, which is the unilateral idea of institutions, catering to the needs of parents to set up courses and inviting experts in relevant professional fields to give lectures. Moreover, there are no uniform and fixed teaching materials. The survey shows that only $24.4 \%$ of the institutions provide uniform teaching materials. From the perspective of curriculum evaluation, interviewees all indicated that there is no unified and standardized curriculum evaluation scheme.

\section{Analysis of Results}

4.1. Analysis of Computational Thinking Models. The problem-solving flowchart contains three subsections, stage design, character design, and game rule design, and concludes with a thought map of the entire work. From the very beginning of learning computational concepts such as action and sequence to the later part of the semester when computational concepts such as data, conditions, and parallelism begin to be involved, students' ideas about completing their work range from simple to complex, from not thinking enough to thinking increasingly clearly. The design of characters and stages also became richer, and the formulation of the relevant rules involved in the work of setting became clearer. However, there were still differences between the groups; some groups finished better and had clear ideas, while others still had some confusion in their ideas in terms of presentation and drawing. The detailed statistics of the problem-solving evaluation are shown in Figure 5.

From Figure 5, it can be seen that the group problemsolving flowchart completion from the beginning of the ideas is not clear enough; in particular the seventh group problem-solving flowchart ideas are very unclea.When discussing with the teaching content layer by layer andcarrying out the problem-solving flowchart training formany times, the group completed the problem-solving flowchart ideas more and more clearly, especially the first group, the second group, and the third group have very good ideas for solving flowchart. Through the process of completing the problem-solving flowchart in small groups, the students' participation gradually increased from being afraid to express themselves and reluctant to participate in the group discussion to being able to actively participate in the group discussion and actively think about the role, background, and setting of relevant rules for the work [19]. It is clear from the changes in students' thinking about problemsolving that they are becoming more proficient in computing concepts, have been gradually exercised in incremental and iterative computing practices, can develop solutions to problems and represent the solution process, and have developed some ability to express and make connections in computing concepts.

$$
B=B_{1}+\frac{t}{T}+P
$$

For microcertification to express a socially constructed vision of learning that is relevant to the learner's identity and interests, it needs to create a badge named after the occupation or role that participants want to engage in, so as to enhance the recognition ability of the badge.

The various computational thinking microcompetencies belong to the academic discourse system in their names and do not apply to microcertification. Therefore, after fully considering the connotations of each indicator and the characteristics of K-12 learners, this study assigned new names to each indicator, thus facilitating the understanding and acceptance of learners, and motivating them to participate in microcertification. The specific correspondence between the computational thinking skills indicators and the microcertification names is shown in Table 1.

To make sense of the microcredentials obtained, it is particularly important to establish a common understanding of microcredentials among those associated with the microcredentialing system, which requires a specific description of each microcompetency. The descriptions of the microcompetencies obtained were sorted out by combining the decomposition of each indicator of computational thinking from existing studies. Current home education is diverse, and in a diverse education home education including computational thinking continues to evolve, so evaluating a child's computational thinking solely based on behavioral performance observed or evidence collected by home parents is not comprehensive, but should integrate the child's behavior in different contexts. Since the decomposition of the resulting competencies is oriented towards the needs of practical assessment, the descriptions of each competency here need to be more tangible, measurable, and operational. For teachers, the competency descriptions can help them design computational thinking assessment programs in a targeted manner; for learners, the competency descriptions can help them establish an understanding of their competency development and planning, to change from passively receiving assessment to actively participating in the assessment, and increase their enthusiasm and initiative to participate in learning. 


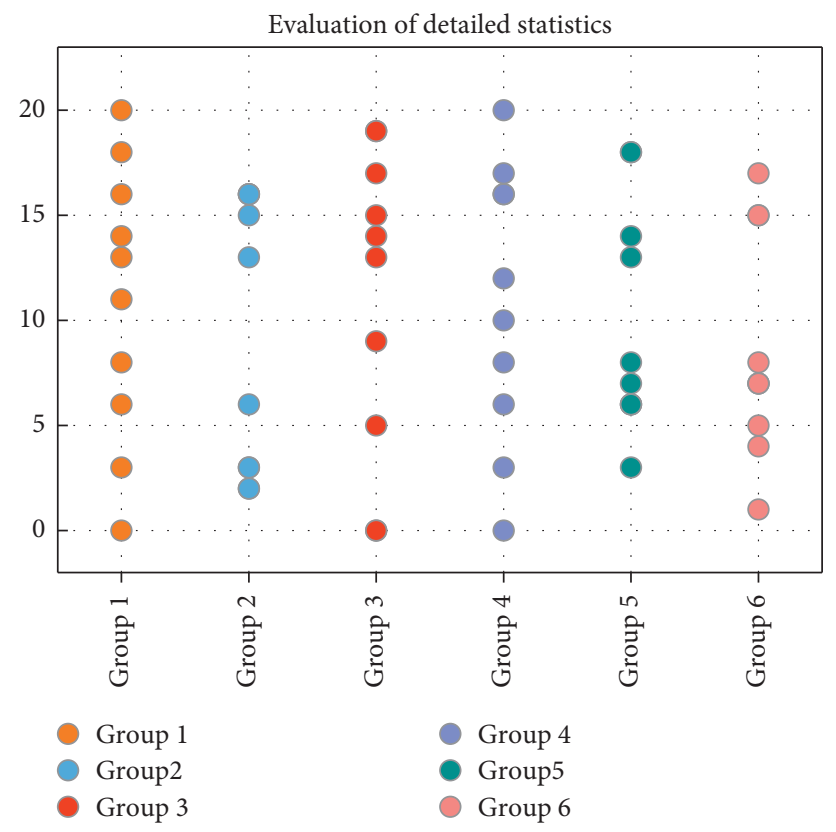

Figure 5: Problem solving flowchart evaluation line chart.

TABLE 1: Correspondence between computational thinking skills indicators and microcertification names.

\begin{tabular}{|c|c|c|}
\hline \multicolumn{3}{|c|}{ Learning content } \\
\hline \multicolumn{2}{|l|}{ Problem transfer ability } & Microauthentication name \\
\hline \multicolumn{2}{|l|}{ Automation capability } & Analogy reasoner \\
\hline \multicolumn{2}{|l|}{ Algorithm design ability } & Programming specialist \\
\hline \multicolumn{2}{|c|}{ Abstract modeling capabilities } & Planning designer \\
\hline \multicolumn{2}{|c|}{$\begin{array}{l}\text { Problem identification and } \\
\text { resolution ability }\end{array}$} & Information refiner \\
\hline \multicolumn{2}{|c|}{ Computational thinking sub-ability } & Problem diagnoser \\
\hline \multicolumn{2}{|l|}{ Thinking ability } & Information collector \\
\hline \multirow{3}{*}{ Computational concept } & Question & Critical thinker \\
\hline & Connect & Collaborative contributor \\
\hline & Express & Technology expresser \\
\hline
\end{tabular}

$$
C=\frac{A-1}{A+B-1}
$$

The implementation of microcertification is mainly to apply the results of the second stage in practice, organize and carry out microcertification, and truly realize microcertification to certify learners' competencies. Firstly, learners select the competencies to be certified according to their own development needs or interests, and then, under the guidance of the certification specification, learners complete the requirements of the task guide and submit relevant evidence, while the microcertification scorers analyze various types of data according to the evaluation criteria and assess the learners' microcertification. The practice of microcertification is flexible in that it can be carried out in a variety of learning venues, both on and off-campus, formal and informal; it can also be combined with the characteristics of the learning activities, and single or multiple microcertifications can be chosen to be carried out in the activities. Putting the designed microcertifications into practice can on the one hand increase learners' motivation to learn and help them become participants and producers in the interest-driven learning process; this setting of learners' active participation in constructing their learning and evaluation achieves a motivational effect and emphasizes learners' subjectivity. On the other hand, the impact of the practice session on computational thinking microcertification is reflected in the fact that practice can test the rationality of each part of the microcertification in terms of design, and according to the effect of practice, it is conducive to making the reverse diagnosis of the microcertification and promoting continuous iteration and improvement of the design of the microcertification.

\subsection{Realization ofFamily Education Optimization} Mechanism. In terms of the parent-child view, parents must understand that a harmonious parent-child relationship is a basis for effective communication and that a good parentchild relationship is the best education. A good parent-child relationship requires parents to do the following two things: first, communicate with their children with their hearts. A harmonious parent-child relationship requires parents to communicate and exchange with their children. First, parents need to have time to communicate with their children; second, parents need to understand their children and find a suitable way to communicate with them. The organic combination of the two can promote the healthy and happy growth of children. Second, let your child vent his or her bad emotions. There are positive and negative emotions. Positive emotions include excitement, serenity, satisfaction, relaxation, etc., while negative emotions include sadness, confusion, frustration, loss, irritability, etc. Positive 
emotions are good, but negative emotions are equally necessary to face in life. Parents who allow their children to vent their emotions appropriately help develop trust in their parents and build a good parent-child relationship [20]. Parents with the right parent-child outlook help their children develop an optimistic outlook on life.

From the beginning, when the experimental and control classes were learning Scratch, there was little difference in the percentage of blocks used in the experimental and control classes. However, as Scratch programming progressed and the number of computational concepts learned increased, the difference between the experimental and control classes gradually began to emerge. In the second half of the semester, the experimental class used the appropriate blocks to complete their work, while the control class used data and arithmetic blocks, but they did not account for as much of the work as the experimental class did. As this aspect also shows, for the same teaching content, the adoption of different teaching modes still has an impact on students' learning outcomes and on the development of their ability to integrate Scratch programming, problem-solving skills, and computational thinking. The computational thinking-oriented teaching mode has a facilitating effect on the programming ability and computational thinking ability of the students in the experimental class. Detailed data statistics are shown in Figure 6.

After the survey, the number of people who fully understand computational thinking, accounting for the total number, shows that the vast majority of secondary school students have a certain understanding of computational thinking after teaching practice, and computational thinking is no longer a completely unfamiliar concept. The survey found that people think that computational thinking is very important in learning and life; the number of people who think that computational thinking does not influence learning and daily life; and the number of people who say that computational thinking has an average influence on learning and daily life, accounting for the total number of people. From the results of the survey, the level of recognition of learning computational thinking among secondary school students is still relatively optimistic, and most of them realize the importance of learning computational thinking and have a high level of enthusiasm for learning computational thinking. The 42 people surveyed attach great importance to the process of transforming book knowledge into practical ability and then into thinking transformation in the process of learning, accounting for the total number of people who said they attached more importance to the process of thinking transformation; people said they attached less importance to the process of thinking transformation from book knowledge into practical ability, accounting for the total number of people. From the results of the survey, secondary school students attach a high degree of importance to the thinking transformation and the development of computational thinking is very necessary. The pedagogues need to guide the learners in the teaching process from theory to practice as a process of thinking transformation to meet the needs of the learners' overall development.

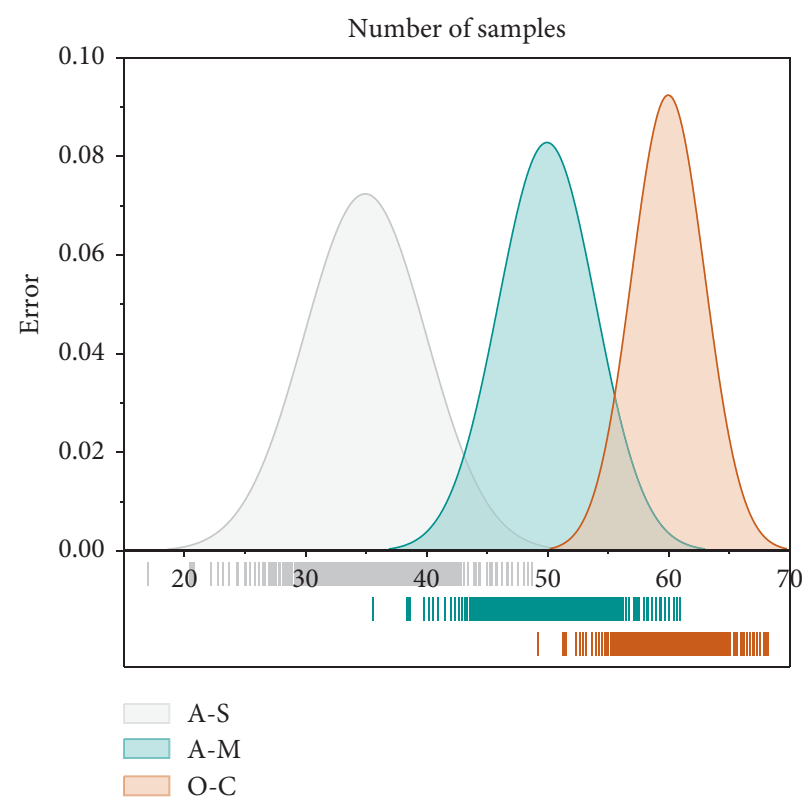

FIGURE 6: Percentage of the control group using each type of building block.

Method selection ratio

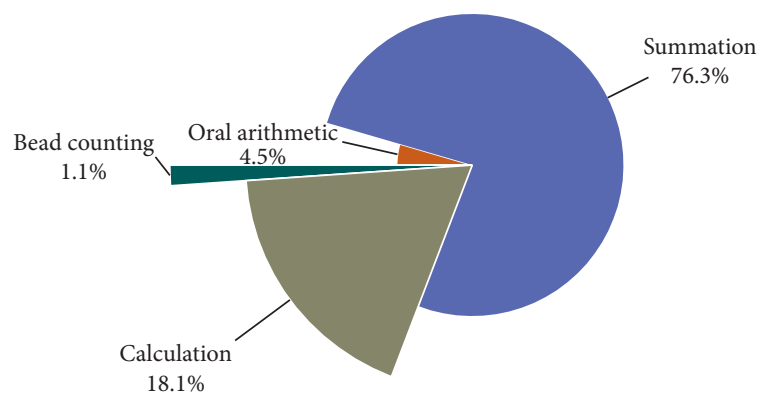

FIGURE 7: Solving for " $1+2+3+4+5+--+98+99+100=$ ?" method to select the ratio.

$$
P=\left\{\begin{array}{cc}
\frac{T_{d}}{T_{1}} & 0<\frac{T_{d}}{T}<1 \\
0 & \frac{T_{d}}{T}>1
\end{array}\right\}
$$

For “ $1+2+3+4+5+--+98+99+100=$ ?", how do you solve this math problem?

As can be seen from Figure 7, asmall number of students chose to use a mathematical calculation to arrive at the result, while more chose to use Gaussian summation to solve the problem. It can be found that, after the model teaching practice, most of the learners' thinking is inspired and they have learned to think about the problem from multiple perspectives and choose the optimal way to solve the problem.

The process of learning is the process of thinking about problems, the process of thinking training, and computational 
thinking as a kind of scientific thinking necessary in the age of technology; the study of its development has a huge role in advancing education and teaching. Exploring the application practice of the model in secondary school IT classroom is only to provide teaching references for most secondary school IT teachers to improve their knowledge of computational thinking. Not only is the teaching goal making learners master computational thinking methods and improve computational thinking ability, but constructing the model, guiding more people to research and think about teaching thinking, introducing computational thinking into other subjects to promote the development of other subject's sound thinking, and cultivating learners' comprehensive scientific thinking is the real purpose of this study.

\section{Conclusion}

The family constitutes the most basic unit of social existence, and its development, like the health of the "cell," affects the normal functioning of the "social body." Due to the influence of the traditional social concept of "family orientation" and "private ownership of children," family education has been treated as a "private matter" within the family. Even though the state has introduced a series of policies to try to intervene in family education activities, the boundaries of such interventions are still obvious due to the influence of traditional concepts, and family education still retains its historical independence. In this paper, we study computational thinking from both theoretical and practical aspects, analyze and discuss how to develop computational thinking skills of family members in home education, and propose a teaching program to develop computational thinking in collaborative IT learning activities, and the good results obtained from the teaching practice confirm the significance of this study. The authors believe that consciously cultivating family members' computational thinking skills in the process of family education, improving family members' cognition of computational thinking, and penetrating computational thinking methods into the whole process of family education can break the traditional model of getting along with family, expand family members' thinking, and enrich the connotation of family education based on computational thinking. Family education cultivation is mainly based on empirical research, theoretical thinking, and experiential learning, but further practical research is needed to test the practical effects of the cultivation model in terms of how operative it is, whether it can be implemented in practice, and whether there are still follow-up problems.

\section{Data Availability}

The data used to support the findings of this study are available from the corresponding author upon request.

\section{Conflicts of Interest}

The authors declare that they have no conflicts of interest.

\section{References}

[1] L. Reuman, J. Thompson-Hollands, and J. S. Abramowitz, "Better together: A review and recommendations to optimize research on family involvement in CBT for anxiety and related disorders," Behavior Therapy, vol. 52, no. 3, pp. 594-606, 2021.

[2] H. Ehsan, A. P. Rehmat, and M. E. Cardella, "Computational thinking embedded in engineering design: capturing computational thinking of children in an informal engineering design activity," International Journal of Technology and Design Education, vol. 31, no. 3, pp. 441-464, 2021.

[3] Y. Bengio, A. Lodi, and A. Prouvost, "Machine learning for combinatorial optimization: A methodological tour d'horizon," European Journal of Operational Research, vol. 290, no. 2, pp. 405-421, 2021.

[4] V. F. Torous, R. W. Simpson, J. P. Balani et al., "College of American pathologists cancer protocols: from optimizing cancer patient care to facilitating interoperable reporting and downstream data use," JCO Clinical Cancer Informatics, vol. 5, no. 5, pp. 47-55, 2021.

[5] T. Brendan and N. R. Nadzli Rozidu, "Optimizing character education for adolescents plagued by free intercourse," Journal of Asian Multicultural Research for Educational Study, vol. 2, no. 1, pp. 5-9, 2021.

[6] M. Guzdial, A. Kay, C. Norris, and E. Soloway, "Computational thinking should just be good thinking," Communications of the ACM, vol. 62, no. 11, pp. 28-30, 2019.

[7] W. Mullens, A. Auricchio, and P. Martens, "Optimized implementation of cardiac resynchronization therapy: a call for action for referral and optimization of care: a joint position statement from the Heart Failure Association (HFA), European Heart Rhythm Association (EHRA), and European Association of Cardiovascular Imaging (EACVI) of the European Society of Cardiology[J]," EP Europace, vol. 23, no. 8, pp. 1324-1342, 2021.

[8] H. I. Haseski, U. Ilic, and U. Tugtekin, "Defining a new 21st century skill-computational thinking: Concepts and trends," International Education Studies, vol. 11, no. 4, pp. 29-42, 2018.

[9] Y.-H. Ching, Y.-C. Hsu, and S. Baldwin, "Developing computational thinking with educational technologies for young learners," TechTrends, vol. 62, no. 6, pp. 563-573, 2018.

[10] D. J. Jones, R. Loiselle, C. Zachary et al., "Optimizing engagement in behavioral parent training: progress toward a technology-enhanced treatment model," Behavior Therapy, vol. 52, no. 2, pp. 508-521, 2021.

[11] D. Zaldivar, E. Cuevas, O. Maciel, A. Valdivia, E. Chavolla, and D. Oliva, "Learning classical and metaheuristic optimization techniques by using an educational platform based on LEGO robots," International Journal of Electrical Engineering Education, vol. 58, no. 2, pp. 286-305, 2021.

[12] C. L. Mozer, P. H. Bhagat, S. A. Seward et al., "Optimizing oral medication schedules for inpatient sleep: A quality improvement intervention," Hospital Pediatrics, vol. 11, no. 4, pp. 327-333, 2021.

[13] M. Sherman, Y. Martynyshyn, and O. Khlystun, "Optimization of the educational environment using information technologies[J]," IJCSNS International Journal of Computer Science and Network Security, vol. 21, no. 4, pp. 80-83, 2021.

[14] M. T. Barakat, N. C. Thosani, R. J. Huang et al., "Effects of a brief educational program on optimization of fluoroscopy to minimize radiation exposure during endoscopic retrograde cholangiopancreatography," Clinical Gastroenterology and Hepatology, vol. 16, no. 4, pp. 550-557, 2018. 
[15] B. Golman and A. Yermukhambetova, "An Excel VBA-based educational module for simulation and energy optimization of spray drying process," Computer Applications in Engineering Education, vol. 27, no. 5, pp. 1103-1112, 2019.

[16] J. G. Fried, J. Pakpoor, C. E. Kahn Jr, and H. M. Zafar, "Lessons from the free-text epidemic: Opportunities to optimize deployment of imaging clinical decision support," Journal of the American College of Radiology, vol. 18, no. 3, pp. 467-474, 2021.

[17] V. V. Baranov, L. P. Ovchinnikova, and O. F. Piralova, "Students adaptation to training in university in educational environment optimization terms[J]," Modern Journal of Language Teaching Methods, vol. 8, no. 7, pp. 67-75, 2018.

[18] A. K. Garber, J. Cheng, E. C. Accurso et al., "Short-term outcomes of the study of refeeding to optimize inpatient gains for patients with anorexia nervosa," JAMA Pediatrics, vol. 175, no. 1, pp. 19-27, 2021.

[19] E. A. Zamora-Cárdenas, A. Pizano-Martínez, and J. M. Lozano-García, "Computational development of a practical educational tool for state estimation of power systems using the MATLAB optimization toolbox[J]," International Journal of Electrical Engineering Education, vol. 56, no. 2, pp. 105-123, 2019.

[20] D. M. Isaacs, D. F. Kruger, and G. R. Spollett, "Optimizing therapeutic outcomes with oral semaglutide: A patient-centered approach," Diabetes Spectrum, vol. 34, no. 1, pp. 7-19, 2021. 